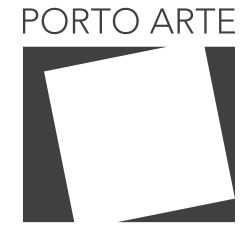

Revista de Artes Visuais

V.25 25.44 Jul/dez 2020 e-ISSN: 2179-8001

\title{
Sobre ser - ou sobre atos da (não) existência
}

About being - or about acts of (non) existence

\section{Chris, The Red}

Universidade Federal do Rio Grande do Sul

ORCID: 0000-0003-3647-6986

\section{Resumo}

Quando criança, chamaram-me de bichinha. Calado, fiquei. | Pensei: na adolescência, mudará. Quando jovem, chamaram-me de traveca. Calada, continuei. Matutei: na fase adulta, acabará. | Quando adulto, abusada fui. Questionei: o que sou? | Nada sou. Não tenho fala. Não tenho identidade e o isolamento imposto, eu já o vivo há anos. Está em cada lágrima, cada chute e olhar. Está nas marcas que carrego, inclusive, as que não podes ver. | E agora, quando idosa, nada pronunciaram, já não se importam.

Palavras-chave:

fotografia, corpo, identidade, existência, poéticas visuais

\section{Abstract}

As a child, they called me a faggot. I was silent. I thought: in adolescence, it will change. I When I was young, they called me a transvestite. I kept silent. I thought: in adulthood, it will end. I As an adult, I was abused. I asked: what am I? I I am nothing. I have no speech. I have no identity and and this imposed isolation, I have lived it for years. It is in every tear, every kick and look. It is in the marks that I carry, including those that you cannot see. IAnd now, as an old, they said nothing, they no longercare.

Keywords: photography, body, identity, existence, visual poetics 


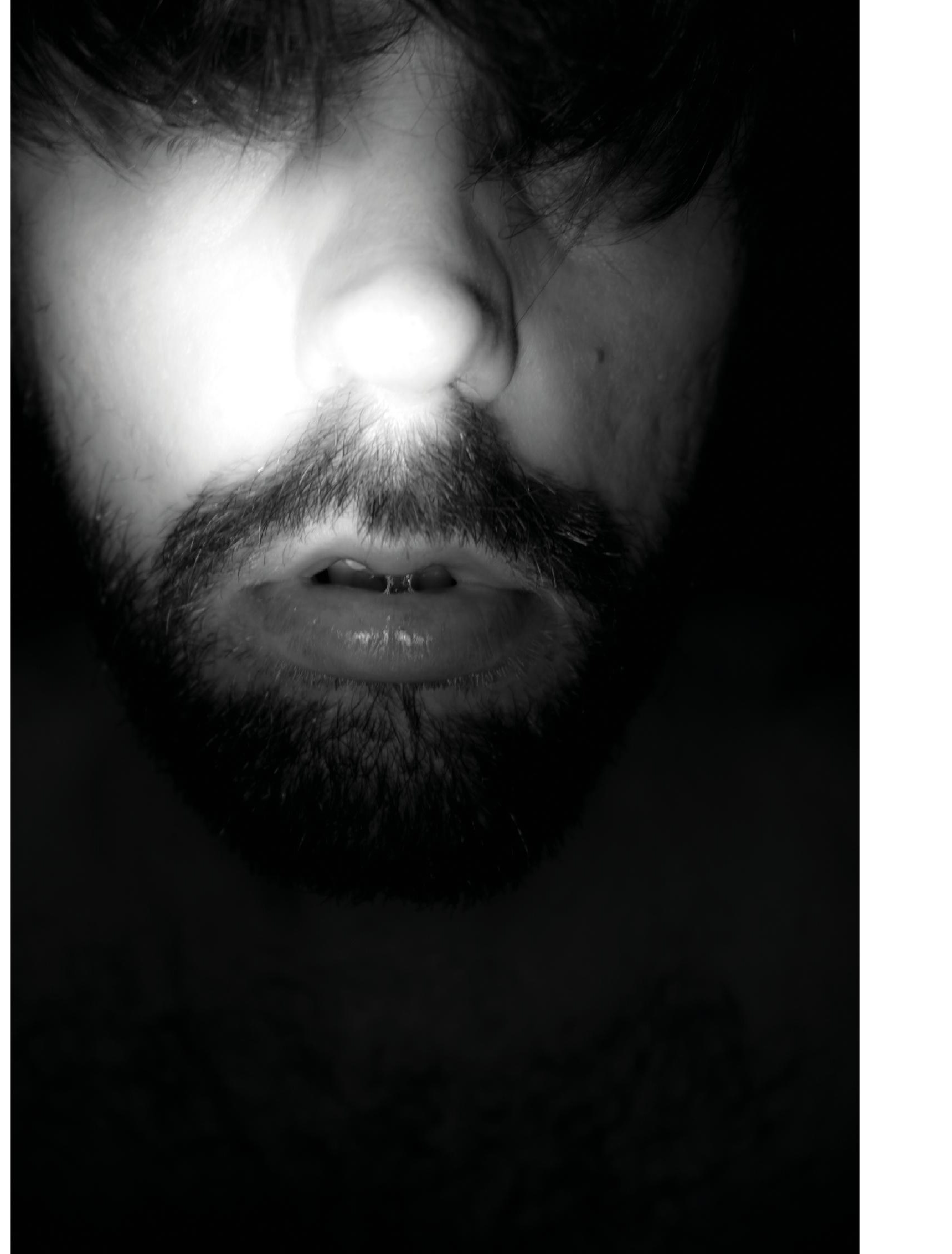




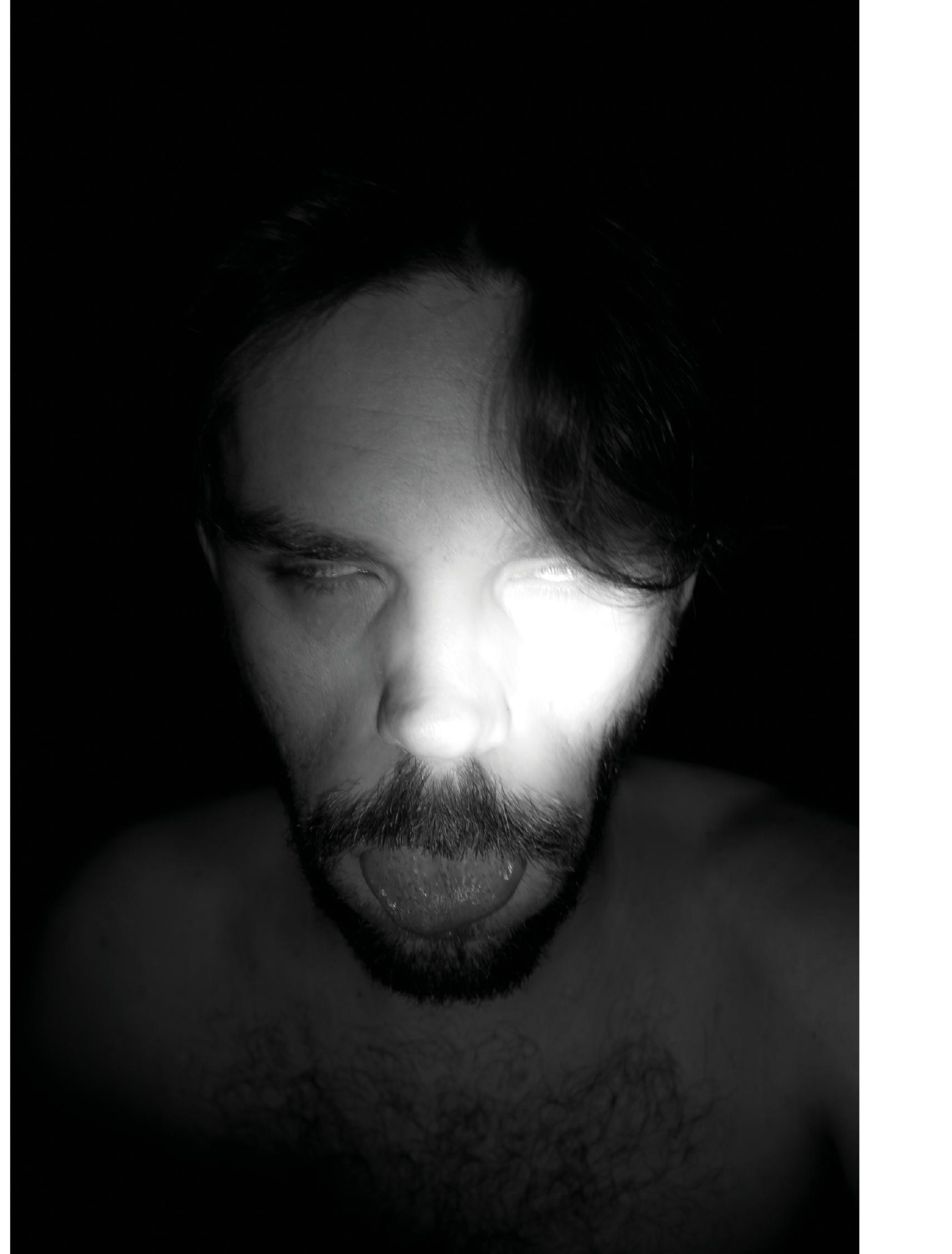




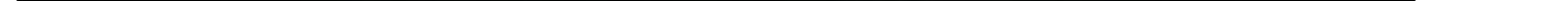




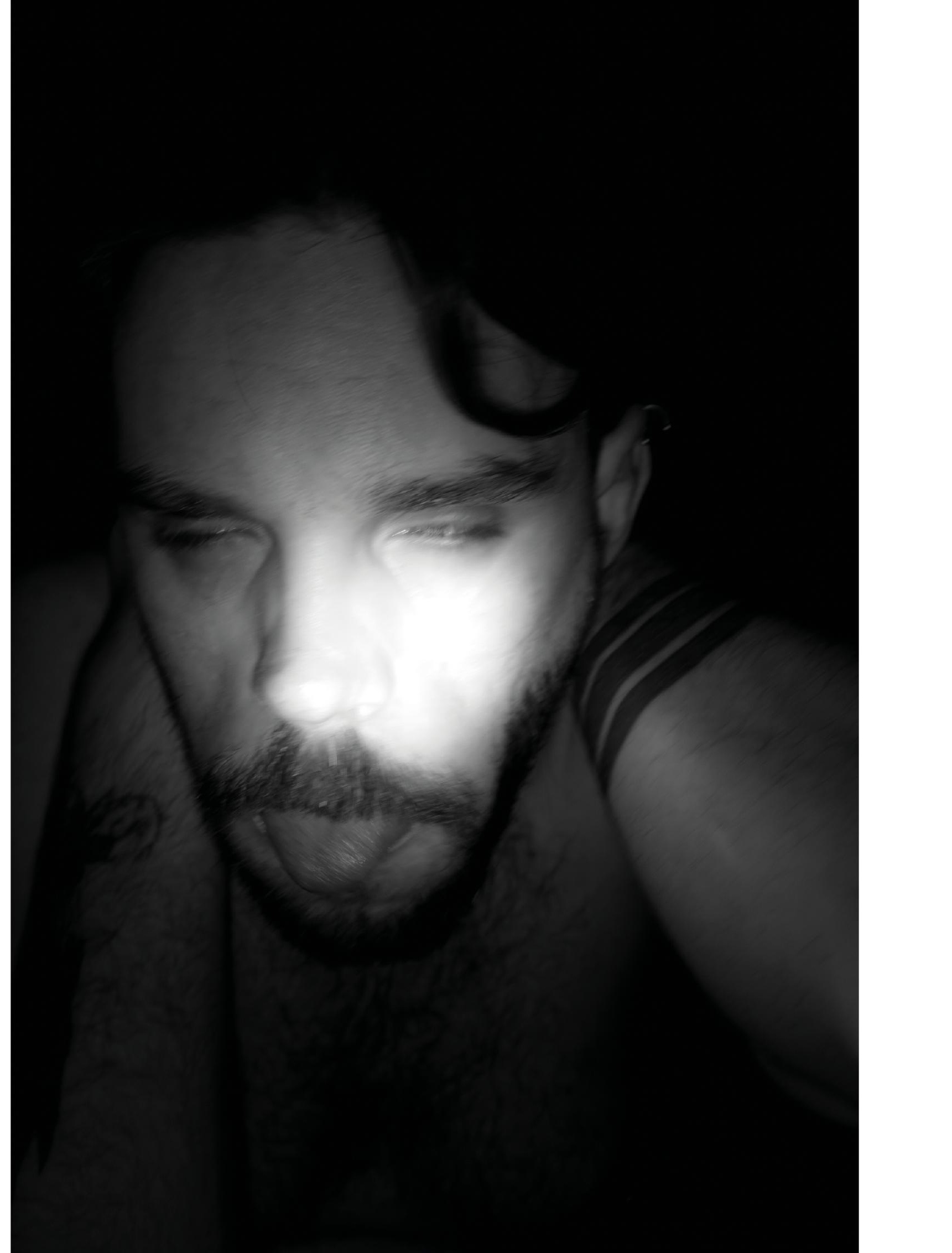




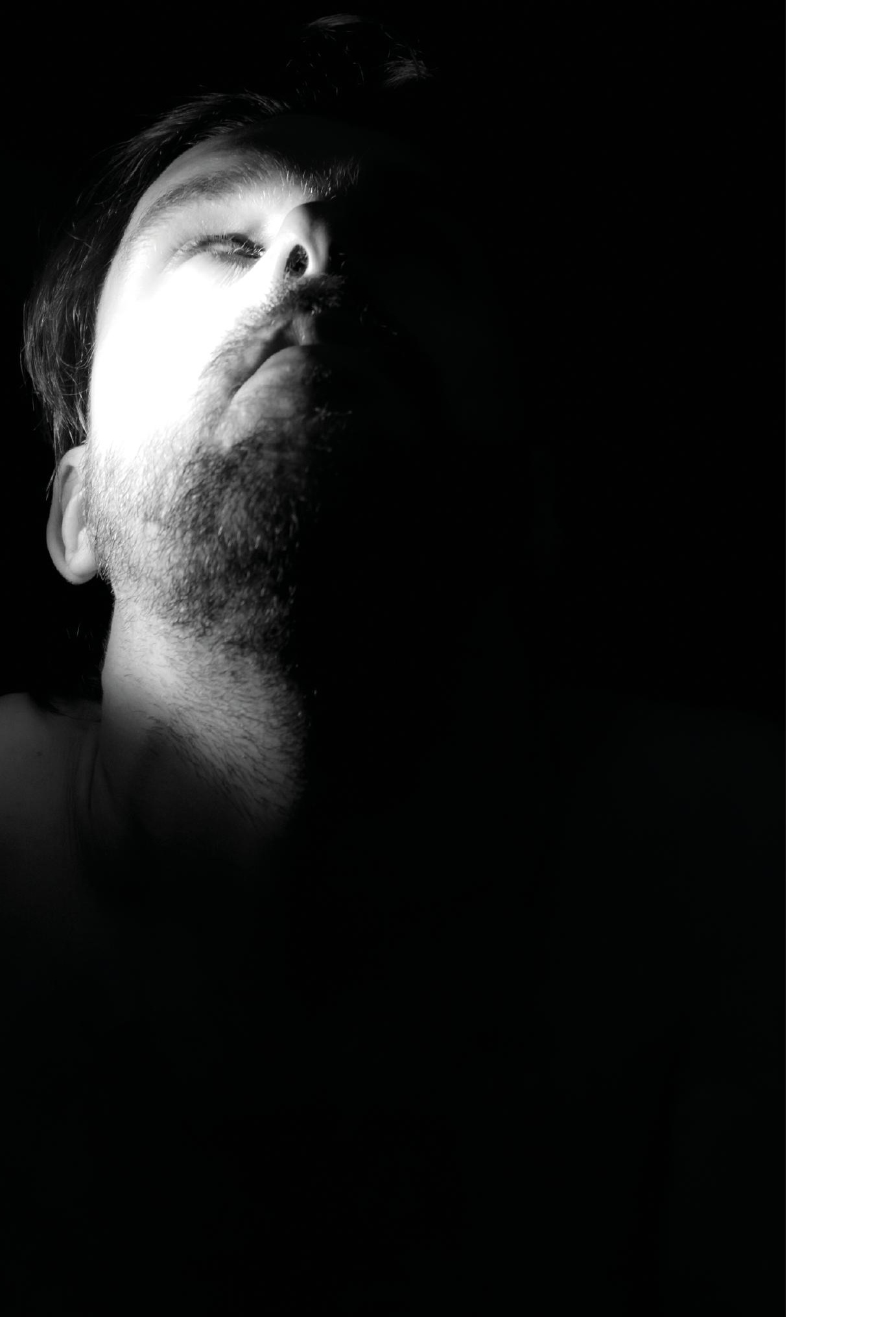




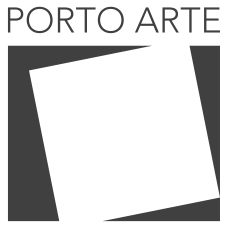

Revista de Artes Visuais

v. $25 \mathrm{n} .44$

\section{Chris, The Red}

Designer gráfico, artista visual, fotógrafo. Em 2002, fundou a The Red Studio, atuando no campo do design e das artes. Na fotografia, explora o campo da contrassexualidade e (pós)pornografia. Trabalhos exibidos em várias cidades, como São Paulo, Rio de Janeiro, Londres, Berlim, entre outras. Bacharel em Relações Internacionais - UnB (2002). Pós-graduado em Especialização em Artes Visuais SENAC/DF (2011). Mestrando em Poéticas Visuais - PPGAV/UFRGS.

Fotos: Modelo Bruno Novadvorski. São Paulo/SP, 2020 